\title{
Comparative Effects of Luteolin and Quercetin on Adipogenesis in 3T3-L1 Cells
}

\author{
Satoru Sakuma*, Midori Yabuuchi, Ayumi Yoshizumi, Yui Okajima, Yohko Fujimoto and \\ Keiichiro Okuhira
}

Department of Environment and Health Sciences, Faculty of Pharmacy, Osaka Medical and Pharmaceutical University, 4-20-1 Nasahara, Takatsuki, Osaka 569-1094, Japan

\section{Article Info:}

Keywords:

Adipocyte differentiation, anti-adipogenic activity,

luteolin,

quercetin,

3T3-L1 cells.

\section{Timeline:}

Received: August 23, 2021

Accepted: September 28, 2021

Published: October 07, 2021

Citation: Sakuma S, Yabuuchi M, Yoshizumi A, Okajima Y, Fujimoto Y, Okuhira K. Comparative Effects of Luteolin and Quercetin on Adipogenesis in 3T3-L1 Cells. J Pharm Nutr Sci 2021; 11.

DOI: https://doi.org/10.29169/1927-5951.2021.11.09

\begin{abstract}
:
Purpose: Quercetin has been reported as a more potent inhibitor of fat accumulation than other flavonoids. However, little information is available regarding the strength and mechanism of the repressive action of luteolin on fat accumulation. Therefore, the aim of the present study was to evaluate the comparative effects of luteolin and quercetin on the differentiation of 3T3-L1 preadipocytes into mature adipocytes.

Methods: 3T3-L1 preadipocytes were differentiated by treatment with insulin, dexamethasone, and 3-isobutyl-1-methylxanthine in the presence of luteolin or quercetin. Alterations in triacylglycerol (TG) levels, lipid-filled adipocyte quantity, and the mRNA and protein expression levels of CCAAT-enhancer-binding protein $\alpha$ $(\mathrm{C} / \mathrm{EBP \alpha})$ and peroxisome proliferator-activated receptor $\mathrm{Y}$ (PPARY) were measured.

Results: Both luteolin and quercetin reduced TG levels, the number of lipid-filled adipocytes, and the mRNA expression levels of C/EBPa and PPARY; however, these effects occurred with lower concentrations of luteolin than quercetin.

Conclusions: These results suggest that luteolin may be more potent than quercetin in inhibiting adipocyte differentiation. These effects may be explained by differences in the inhibitory effects of the two compounds on C/EBPa and PPARY expression. This study suggests that luteolin might be a beneficial dietary supplement for obesity and lifestyle-related diseases.
\end{abstract}

${ }^{*}$ Corresponding Authors

Tel: +81726901055; +81726901210

Fax: +81726901055; +81726901210

E-mail: satoru.sakuma@ompu.ac.jp, keiichiro.okuhira@ompu.ac.jp

(c) 2021 Sakuma et al.; Licensee SET Publisher.

This is an open access article licensed under the terms of the Creative Commons Attribution Non-Commercial License (http://creativecommons.org/licenses/by-nc/3.0/) which permits unrestricted, non-commercial use, distribution and reproduction in any medium, provided the work is properly cited. 


\section{INTRODUCTION}

Obesity is a serious health problem worldwide that continuously increases the morbidity and mortality associated with several acute and chronic diseases such as dyslipidemia, hypertension, type 2 diabetes, and cardiovascular disease $[1,2]$. Obesity is characterized by increases in the number (hyperplasia) and size (hypertrophy) of adipocytes [3], which are regulated by genetic, metabolic, and nutritional factors [4]. Therefore, deciphering the mechanism by which certain nutrients affect adipocyte differentiation is important for the prevention of obesity and other related conditions.

The molecular mechanisms of adipocyte differentiation have been extensively studied using progenitor adipocyte culture systems $[5,6]$. Progenitor adipocytes undergo growth arrest and eventually differentiate into adipocytes. This is accompanied by a dramatic increase in the expression of adipocyte genes, such as adipocyte fatty acid-binding proteins and lipid metabolism enzymes. The growth and differentiation of preadipocytes are regulated by communication between individual cells or between cells and the extracellular environment. Various hormones and growth factors that positively or negatively affect adipocyte differentiation have also been identified. However, studies to identify the regulatory regions of adipocyte-specific gene clusters have shown that the transcription factors peroxisome proliferator-activated receptor Y (PPARY) and CCAAT/enhancer-binding protein $\alpha(\mathrm{C} / \mathrm{EBP} \alpha)$ are mainly involved in complex transcriptional processes during adipocyte differentiation via the PPAR response element.

Some flavonoids, which are widely present in edible plants, have been demonstrated to inhibit fat accumulation in cultured cells and may be beneficial to human health through their anti-obesity effects [7-10]. For example, Iwashita et al. [9] reported that flavonols, especially quercetin, had a significantly lower effect on glycerol-3-phosphate dehydrogenase activity, a hallmark of adipocyte differentiation, compared with the effects of other flavonoids with basic structures. Additionally, Oil Red O staining indicated lower lipid accumulation in adipocytes following treatment with the flavonols, especially with quercetin. Mosqueda-Solis et al. [10] also showed that quercetin is more potent than other flavonoids with respect to the downregulation of sterol regulatory element-binding protein 1c mRNA, which leads to the repression of adipocyte differentiation.
Luteolin is a crucial member of the flavones that is widely found in vegetables, fruits, and natural herbal drugs such as parsley, thyme, peppermint, and celery, and has been attracting recent attention as a substance with potent antioxidant, anti-cancer, and anti-inflammatory properties by inhibiting nuclear factor kappa B (NF-kB) activation and inducing apoptosis [1113]. However, little information is available regarding the strength and mechanism of the repressive action of luteolin on adipocyte differentiation.

In the present study, the comparative effects of luteolin and quercetin on the differentiation of 3T3-L1 preadipocytes into mature adipocytes were evaluated. Additionally, the effects of the two compounds on the C/EBPa- PPARY pathway during adipocyte differentiation were investigated.

\section{MATERIALS AND METHODS}

\section{Ethics Declaration}

No ethical approval was necessary as the present study did not involve human or animal subjects.

\section{Materials}

Mouse 3T3-L1 preadipocytes were obtained from the European Collection of Cell Cultures (Wiltshire, UK). Transcriptor First Strand cDNA Synthesis Kit and LightCycler FirstStart DNA Master ${ }^{\text {plus }}$ SYBR green reagent were obtained from Roche Diagnostics (Indianapolis, IN, USA). TRIzol reagent and the primers for $\beta$-actin, PPARy, and C/EBPa were purchased from Invitrogen (Carlsbad, CA, USA). Luteolin, quercetin, and a protease inhibitor cocktail were obtained from Sigma Chemical Co. (St. Louis, MO, USA). Triglyceride E-test Wako kit was obtained from Wako Pure Chemical Industries, Ltd. (Osaka, Japan). Lipid Droplets Fluorescence Assay Kit was obtained from Cayman Chemical Co. (Ann Arbor, MI, USA). All other reagents used were of analytical grade.

\section{Cell Culture}

3T3-L1 preadipocytes were cultured at $37^{\circ} \mathrm{C}$ in a humidified atmosphere of $5 \% \mathrm{CO}_{2} / 95 \%$ air. The cells were maintained in Dulbecco's modified Eagle's medium supplemented with $10 \%$ fetal bovine serum and $1 \%$ penicillin-streptomycin (growth medium). Cell differentiation was induced according to the protocol for 3T3-L1 preadipocytes obtained from the European Collection of Cell Cultures. The procedure was initiated 2 days after confluence, and performed for 3 days in 
the growth medium supplemented with $0.25 \mu \mathrm{M}$ dexamethasone, $0.5 \mathrm{mM}$ 3-isobutyl-1-methylxanthine (IBMX), and $1 \mu \mathrm{g} / \mathrm{mL}$ insulin (differentiation medium, DM). This was followed by 2 days of culture in the growth medium supplemented with $1 \mu \mathrm{g} / \mathrm{mL}$ insulin (maturation medium). Thereafter, the cells were cultured in the growth medium for 2 days.

Treatment with various drugs during differentiation of the 3T3-L1 preadipocytes, subsequent Oil Red $O$ staining, and determination of triacylglycerol (TG) levels, the number of lipid-filled adipocytes, and the mRNA expression levels of PPARY and C/EBPa were performed according to our previously reported methods [14-16].

\section{Treatment with Luteolin or Quercetin}

Luteolin and quercetin were prepared in dimethyl sulfoxide $\left(\mathrm{Me}_{2} \mathrm{SO}\right)$ and added to the growth, initiation, and maturation media from day 3 (time of addition of dexamethasone, IBMX, and insulin) to day 9 (end of the experiment). The $\mathrm{Me}_{2} \mathrm{SO}$ concentration was maintained at $0.25 \%$ of the total volume of the medium. Preliminary experiments demonstrated no significant effects of $0.25 \% \mathrm{v} / \mathrm{v} \mathrm{Me}_{2} \mathrm{SO}$ on cell differentiation.

\section{Oil Red O Staining}

The cells were fixed in $4 \%$ formaldehyde-phosphate buffer $(\mathrm{pH} 7.4)$ for $1 \mathrm{~h}$, rinsed with water, and stained with $0.3 \%$ Oil Red $\mathrm{O}$ dye for $1 \mathrm{~h}$. After washing again with water, the cells were observed under a microscope (10 × 20 magnification).

\section{Quantification of Mature Adipocytes}

Mature adipocytes in the culture were quantified using the Lipid Droplets Fluorescence Assay Kit and flow cytometry. The cells were carefully trypsinized and centrifuged at $200 \times g$ for $5 \mathrm{~min}$ at $4^{\circ} \mathrm{C}$. The cell pellet was resuspended, fixed, and stained with the lipophilic fluorescent dye Nile red according to the manufacturer's instructions. The samples were then analyzed using a BD FACSAria III flow cytometer (Becton Dickinson, Basel, Switzerland). Nile red fluorescence was measured on the FL2 (FITC-A) emission channel through a $585 \pm 21 \mathrm{~nm}$ bandpass filter following excitation with an argon ion laser source at $488 \mathrm{~nm}$. Using a forward scatter/side scatter representation of events, the $\mathrm{P} 1$ region was defined to exclude cellular debris from the analysis. A selection window (P2) was then selected as the area with high FL2 (FITC-A) values (mature adipocytes) in the FL2
(FITC-A)/cell count blot of the $\mathrm{P} 1$ population, as described by Sottile and Seuwen [17]. Data analysis was performed using the BD FACSDiva software (ver. 8.0, Becton Dickinson). For each sample, 20,000 events were recorded. The results are expressed as the percentage of cells in the $\mathrm{P} 2$ region.

\section{Determination of TG Levels}

The cells were harvested by scraping them from the culture dishes into lysis buffer (1\% Triton X-100, 150 $\mathrm{mM} \mathrm{NaCl}, 4 \mathrm{mM}$ ethylenediaminetetraacetic acid, and $20 \mathrm{mM}$ Tris- $\mathrm{HCl}[\mathrm{pH}$ 7.4] containing a protease inhibitor cocktail) and lysed completely using a horn-type sonicator. The TG level, which is an index of lipid accumulation, was determined using the Triglyceride Etest Wako kit following normalization of the protein amounts and expressed as TG content $(\mu \mathrm{g} / \mathrm{mg}$ protein).

\section{Determination of the mRNA Expression Levels of $\beta$ - Actin, PPARY, and C/EBPa}

Untreated cells, as well as those treated with luteolin up to day 5 , were washed with ice-cold phosphatebuffered saline. Total cellular RNA was prepared using TRIzol reagent. One microgram of total RNA was reverse-transcribed into cDNA using the Transcriptor First Strand cDNA Synthesis Kit. The concentration and quality of the purified total RNA were determined spectrophotometrically at $260 \mathrm{~nm}$. The ratio of optical density (OD) at $260 \mathrm{~nm}$ to that at $280 \mathrm{~nm}\left(\mathrm{OD}_{260: 280}\right)$ was also calculated. Next, mRNA expression was determined by real-time reverse transcriptionpolymerase chain reaction using SsoAdvanced ${ }^{\mathrm{TM}}$ SYBR $^{\circledR}$ Green Supermix reagent and a CFX Connect ${ }^{\mathrm{TM}}$ instrument. The results are expressed as the target mRNA level relative to that of $\beta$-actin mRNA, and the values obtained in the presence or absence of the drugs are expressed relative to the values associated with exposure to the DM alone.

The primers used for $\beta$-actin, PPARy, and C/EBPa amplification were as follows: $\beta$-actin, 5'-ACACCCC AGCCATGTACG-3', and 5'-TGGTGGTGAAGCTGTA GCC-3'; PPARY, 5'-GTGAAGCCCATCGAGGACA-3', and 5'-TGGAGCACCTTGGCGAACA-3'; and C/EBPa, 5'-ATGGTTTCGGGTCGCTGGAT-3', and 5'CCACGGC CTGACTCCCTCAT-3'.

\section{Statistical Analysis}

The results are expressed as mean \pm standard error of the mean. Significant differences in data between two 
groups were assessed using t-tests, whereas differences among multiple groups were assessed using one-way analysis of variance followed by Scheffé's multiple range test. Differences were considered statistically significant at $P<0.05$.

\section{RESULTS}

\section{Luteolin Suppresses the Differentiation of 3T3-L1 Cells more Potently than Quercetin}

Figure 1 shows the effects of luteolin and quercetin on TG accumulation in the 3T3-L1 adipocytes. The level of TG in the DM cells was 7-8 times higher than that in the control cells. However, luteolin decreased the TG content in a concentration-dependent manner (4-95\% inhibition) at concentrations ranging from 10 to $100 \mu \mathrm{M}$. Conversely, quercetin showed no significant effect on TG accumulation at concentrations up to $50 \mu \mathrm{M}$. At 50 $\mu \mathrm{M}$, luteolin reduced TG accumulation almost to the same extent as GW9662, an antagonist of PPARY [18]. As shown in Figure 2A and 2B, the numbers of Oil Red O-stained cells and of lipid-filled adipocytes in the DM cells were greater than those in the control cells. Luteolin reduced the number of fat droplets in the cells in a concentration-dependent manner when tested at concentrations of 10, 25, and $50 \mu \mathrm{M}$ (Figure 2A). Compared to cells that were exposed to DM alone, cells that were exposed to luteolin $(25$ and $50 \mu \mathrm{M})$ also showed significant decreases in the percentage of lipidfilled adipocytes in the Nile red staining and flow cytometry experiments (Figure 2B; $34 \%$ and $45 \%$ inhibition, respectively). In contrast, quercetin showed no effect on the number of Oil Red O-stained cells or the percentage of lipid-rich adipocytes at concentrations up to $50 \mu \mathrm{M}$.

These results indicated that luteolin inhibits the differentiation of 3T3-L1 adipocytes more potently than quercetin, suggesting that the anti-obesity effect of luteolin is higher than that of quercetin.

\section{Luteolin Decreases the mRNA Expression Levels of PPARY and C/EBPa}

The DM cells showed markedly higher mRNA expression levels of PPARY and C/EBPa than the control cells. The mRNA expression levels of PPARY and C/EBPa were significantly suppressed by luteolin at 25 and $50 \mu \mathrm{M}$ (PPARy mRNA, 39\% and 52\% inhibition; C/EBPa mRNA, $38 \%$ and $51 \%$ inhibition) (Figure 3) but were unaffected by quercetin at concentrations up to $50 \mu \mathrm{M}$.

These results indicated that luteolin had an inhibitory effect on the mRNA expression of PPARy and C/EBPa in the 3T3-L1 cells, and disrupted adipocyte differentiation through the C/EBPa-PPARy pathway.

\section{DISCUSSION}

PPARy functions as a master regulator of adipocyte differentiation, whereas C/EBPa works with PPARy to induce adipocyte differentiation $[5,6]$. In this study, we found that luteolin reduced TG accumulation in a concentration-dependent manner (at 10-100 $\mu \mathrm{M}$ ), fat droplet formation (at 10, 25, and $50 \mu \mathrm{M}$ ), and the

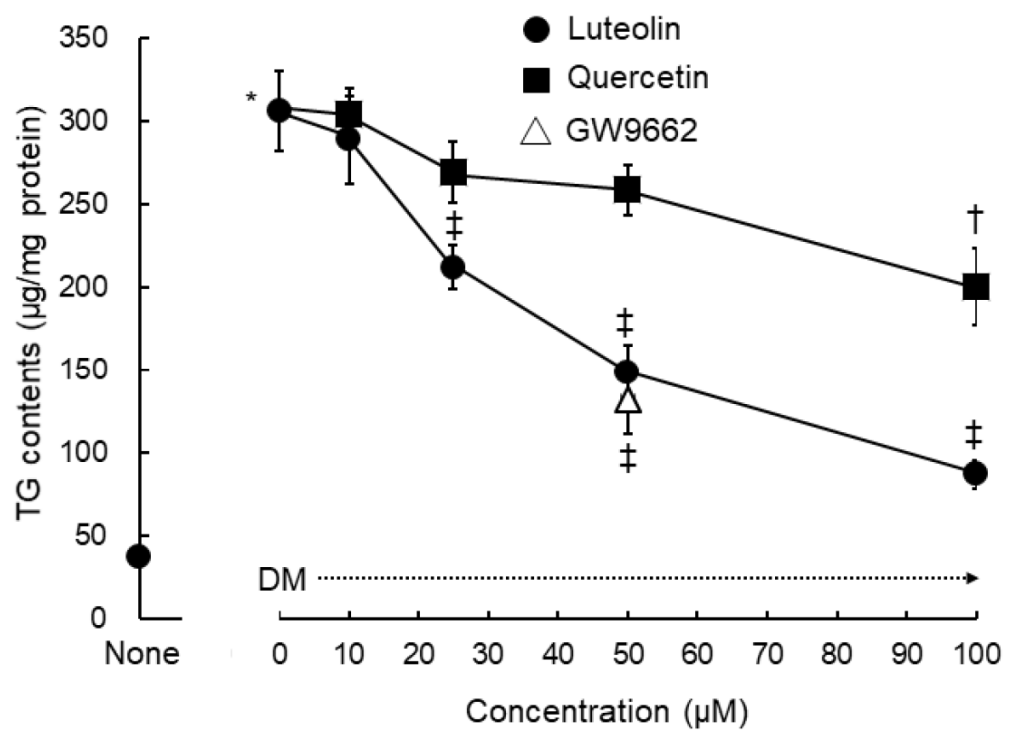

Figure 1: Alteration in triacylglycerol (TG) levels in 3T3-L1 adipocytes treated with luteolin or quercetin. Data are presented as mean \pm standard error of the mean $(\mathrm{n}=4-8)$. ${ }^{\star} P<0.01$ compared with untreated cells (None). ${ }^{\dagger} P<0.05$ and ${ }^{\ddagger} P<0.01$ compared with cells cultured in the differentiation medium (DM). 

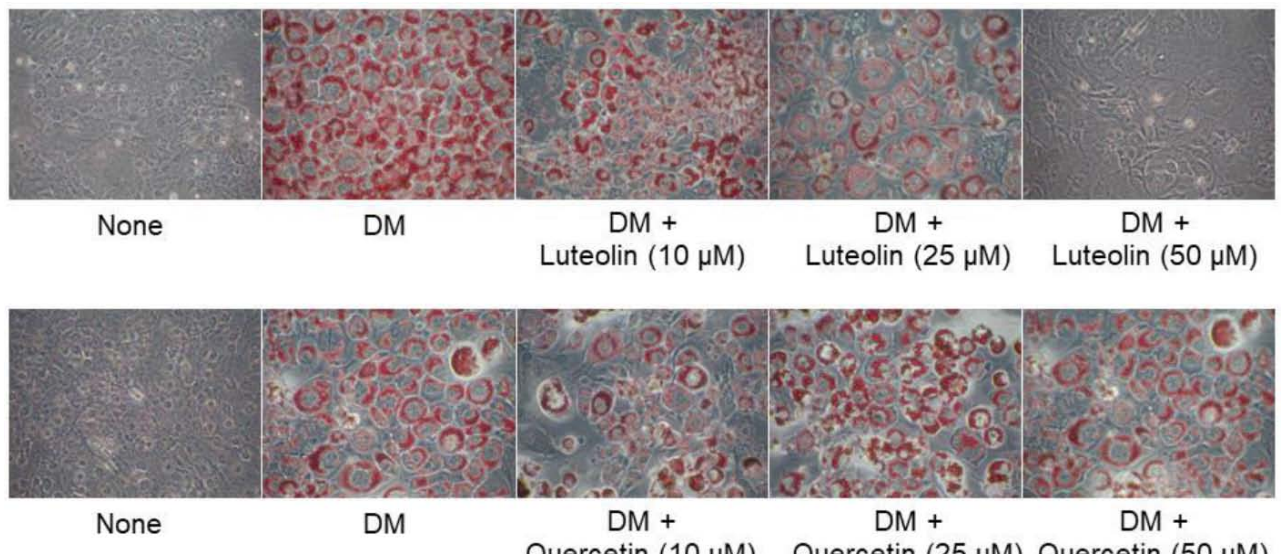

A

a)

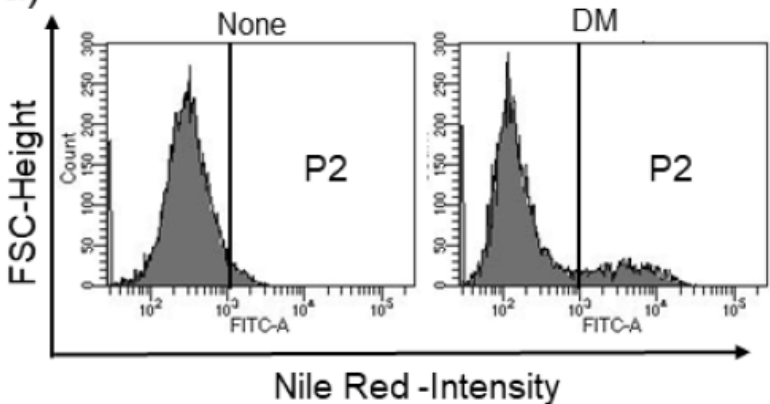

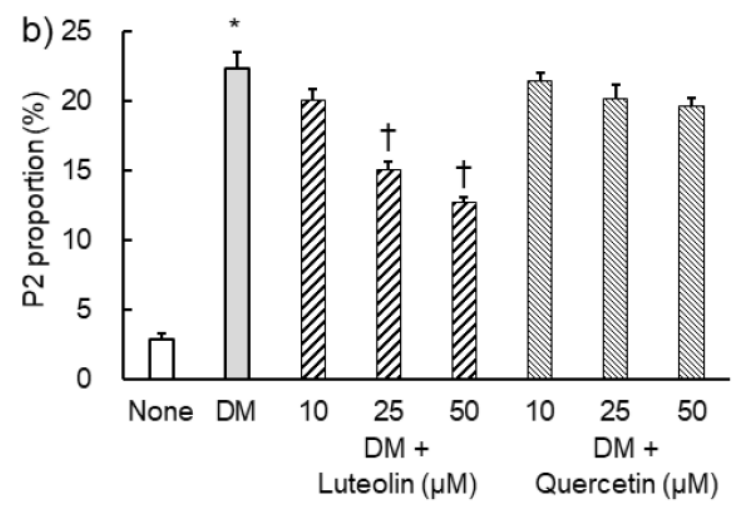

B

Figure 2: Alterations in (A) Oil Red $O$ staining, and (B) Nile red staining and flow cytometric analysis of 3T3-L1 adipocytes treated with luteolin or quercetin. (A) Representative images from six independent experiments. (B) a) Representative images showing results of the flow cytometric analysis using Nile red staining. b) Data are presented as mean \pm standard error of the mean $(\mathrm{n}=5) .{ }^{\star} P<0.01$ and ${ }^{\dagger} P<0.01$ compared with untreated cells (None) and the cells cultured in the differentiation medium (DM), respectively. FSC, forward scatter.

percentage of lipid-rich adipocytes (at 25 and $50 \mu \mathrm{M}$ ). Moreover, our results indicate that luteolin suppresses the induction of 3T3-L1 cell differentiation partially by reducing PPARY and C/EBPa mRNA expression.

The mechanism by which luteolin inhibits adipocyte differentiation more potently than quercetin remains unclear. Studies have shown that adipogenesis is correlated with various signaling pathways such as insulin signaling and the PPAR regulation pathway, which are promising drug targets in the treatment of obesity and metabolic diseases $[19,20]$. The catalytic ability of the insulin receptor (IR) is dependent on the expression levels of IRs and the tyrosine phosphorylation of IR substrate 1. IR signaling leads to activation of the serine/threonine-protein kinase $B$ and phosphatidylinositol 3-kinase signaling pathways, which can further lead to activation of the C/EBPaPPARy pathway. Gebhardt [21] reported that among the known constituents in artichoke extracts, luteolin is mainly responsible for blocking the effect of insulin on cholesterol biosynthesis. Activation of NF-kB results in reduced insulin signaling [22]. Furthermore, it has been reported that luteolin potently activates NF-KB [23]. Thus, further investigation is needed to determine whether these pathways are also more potently affected by luteolin than by quercetin.

$\mathrm{Xu}$ et al. [24] have shown that a luteolin-mixed diet $(0.01 \% \mathrm{w} / \mathrm{w}, 12$-week treatment) ameliorates various effects of a high-fat diet in mice. In their study, luteolin suppressed the infiltration of mast cells and macrophages into adipose tissue, reduced inflammatory cytokine levels in the adipose tissue, and suppressed mast cell-derived interleukin- 6 expression. Therefore, it was suggested that luteolin stabilizes mast cells and improves various metabolic activities. Kwon et al. [25] reported that the expression of genes in the fatty acid synthesis system, as well as those involved in lipolysis and the tricarboxylic acid (TCA) cycle, are upregulated in the adipose tissue. Additionally, a diet supplemented with luteolin increases fatty acid 

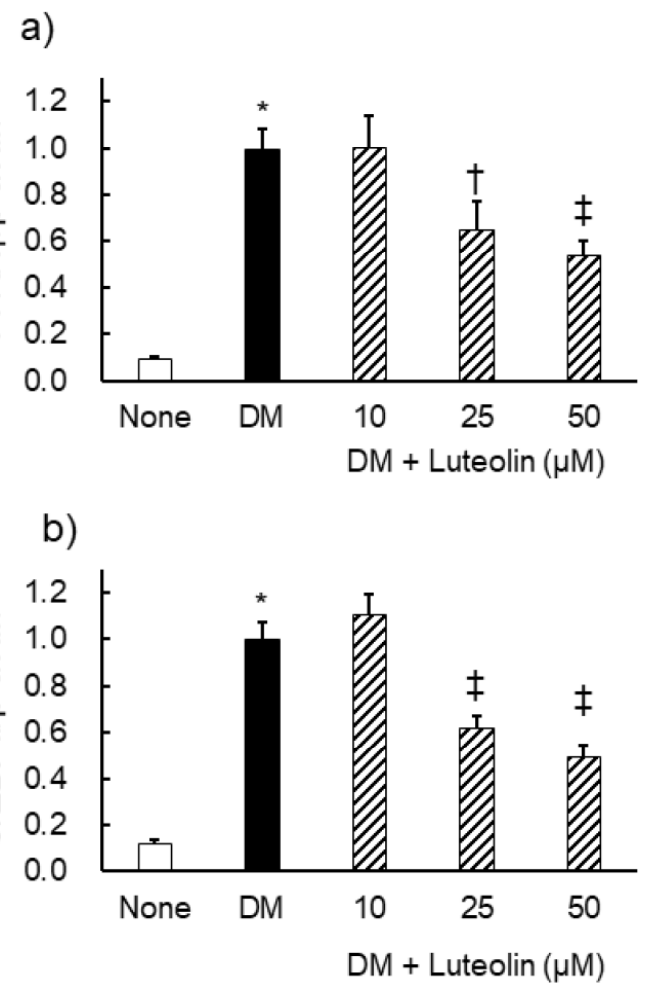

c)

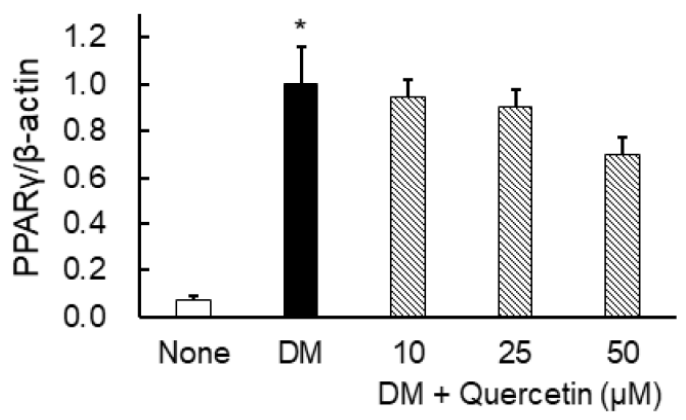

d)

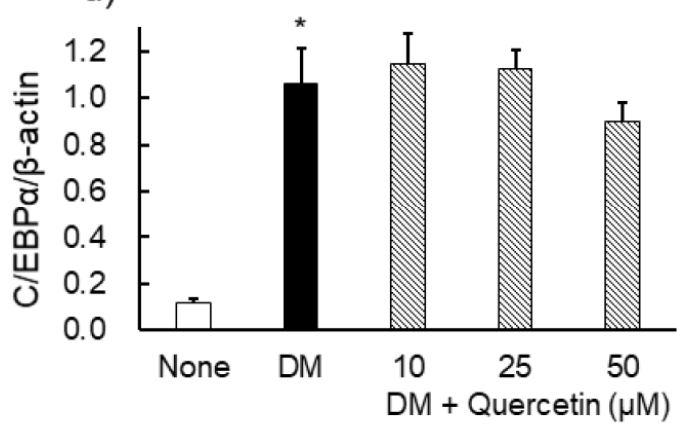

Figure 3: Alterations in the mRNA expression levels of peroxisome proliferator-activated receptor $\mathrm{Y}$ (PPARY) and CCAATenhancer binding protein $\alpha(\mathrm{C} / \mathrm{EBP} \alpha)$ in 3T3-L1 adipocytes treated with luteolin $(\mathbf{a}, \mathbf{b})$ or quercetin $(\mathbf{c}, \mathbf{d})$. Data are presented as mean \pm standard error of the mean $(\mathrm{n}=3-4)$. ${ }^{\star} P<0.01$ compared with untreated cells (None). ${ }^{\dagger} P<0.05$ and ${ }^{\ddagger} P<0.01$ compared with cells cultured in the differentiation medium (DM).

synthesis in the adipose tissue but promotes lipolysis and the TCA cycle, thereby suppressing the formation of fat droplets, leading to a reduction in fat mass (antiobesity effect). Luteolin is believed to exhibit potent antioxidant, anti-tumor, and anti-inflammatory effects [11-13]. Furthermore, this crucial member of the flavones may also have potent ameliorative effects against diet-induced obesity and IR, through inhibition of mast cells and macrophages infiltration [24] and upregulation of lipolysis and the TCA cycle [25], as well through strong inhibition of adipocyte differentiation as observed in the present study.

Luteolin is naturally found in a wide array of vegetables, fruits, and herbs such as parsley, thyme, peppermint, and celery. Most people, especially those with a healthy diet and no neurological disorders, can benefit from increasing the amount of foods that contain natural luteolin and other polyphenols. Since dietary supplements containing luteolin are available on the market, mainly because it is expected to be effective for gout [26, 27], this study suggests that people suffering from increased body fat or obesity may also benefit from dietary supplements containing luteolin.

\section{CONCLUSION}

The results suggest that luteolin may be more potent than quercetin in inhibiting adipocyte differentiation, which may be related to differences in the inhibitory effects of the two compounds on C/EBPa and PPARY expression. These findings suggest that luteolin may be a more effective prophylactic drug candidate than quercetin. In future studies, we aim to investigate the mechanism of action of luteolin by studying its structure-activity relationship and the medicinal effects of its derivatives, as we hope to contribute to the discovery of preventive drugs against obesity and lifestyle-related diseases for the maintenance and promotion of human health.

\section{CONFLICT OF INTEREST}

None to declare.

\section{SUPPORTING AGENCIES}

None.

\section{AUTHOR CONTRIBUTIONS}

Satoru Sakuma: Conceptualization, Methodology, Investigation, Validation, Writing - original draft 
Keiichiro Okuhira: Project administration, Writing review \& editing, Supervision, Funding acquisition

Yohko Fujimoto: Project administration, Supervision, Funding acquisition

Midori Yabuuchi, Ayumi Yoshizumi, and Yui Okajima: Investigation, Validation

\section{ABBREVIATIONS}

$\mathrm{C} / \mathrm{EBP} \alpha=$ CCAAT-enhancer-binding protein $\alpha$

$\mathrm{DM} \quad=$ differentiation medium

IBMX = 3-isobutyl-1-methylxanthine

IR $\quad=$ insulin receptor

$\mathrm{Me}_{2} \mathrm{SO}=$ dimethyl sulfoxide

$\mathrm{NF}-\mathrm{kB}=$ nuclear factor kappa $\mathrm{B}$

OD = optical density

PPARY $=$ peroxisome proliferator-activated receptor $\mathrm{y}$

TCA = tricarboxylic acid

TG = triacylglycerol

\section{REFERENCES}

[1] Hossain P, Kawar B, El Nahas M. Obesity and diabetes in the developing world-a growing challenge. New Engl J Med 2007; 356(3): 213-215.

https://doi.org/10.1056/NEJMp068177

[2] Mello MM, Studdert DM, Brennan TA. Obesity-the new frontier of public health law. New Engl J Med 2006; 354(24): 2601-2610. https://doi.org/10.1056/NEJMhpr060227

[3] de Ferranti S, Mozaffarian D. The perfect storm, obesity, adipocyte dysfunction: and metabolic consequences. Clin Chem 2008; 54(6): 945-955 https://doi.org/10.1373/clinchem.2007.100156

[4] Kopelman PG. Obesity as a medical problem. Nature 2000; 404(6778): 635-643. https://doi.org/10.1038/35007508

[5] Gregoire FM, Smas CM, Sul HS. Understanding adipocyte differentiation. Physiol Rev 1998; 78(3): 783-809. https://doi.org/10.1152/physrev.1998.78.3.783

[6] Ali AT, Hochfeld WE, Myburgh R, Pepper MS. Adipocyte and adipogenesis. Eur J Cell Biol 2013; 92(6-7): 229-236. https://doi.org/10.1016/j.ejcb.2013.06.001

[7] Agullo G, Gamet-Payrastre L, Manenti S, Viala C, Remesy C, $\mathrm{Chap} \mathrm{H}$, et al. Relationship between flavonoid structure and inhibition of phosphatidylinositol 3-kinase: a comparison with tyrosine kinase and protein kinase $\mathrm{C}$ inhibition. Biochem Pharmacol 1997; 53(11): 1649-1657. https://doi.org/10.1016/S0006-2952(97)82453-7

[8] Herrmann K. Flavonols and flavones in food plants: a review. Int J Food Sci Technol 1976; 11(5): 433-438. https://doi.org/10.1111/j.1365-2621.1976.tb00743.x
Iwashita K, Yamaki K, Tsushida T. Effect of flavonoids on the differentiation of 3T3-L1 adipocytes. Food SciTechnol Res 2001; 7(2): 154-160 https://doi.org/10.3136/fstr.7.154

[10] Mosqueda-Solis A, Lasa A, Comez-Zorita S, Eseberri I, Pico C, Portillo MP. Screening of potential anti-adipogenic effects of phenolic compounds showing different chemical structure in 3T3-L1 preadipocytes. Food Funct 2017; 8(10): 35763586.

https://doi.org/10.1039/C7FO00679A

[11] Kim SH, Shin KJ, Kim D, Kim YH, Han MS, Lee TG, et al. Luteolin inhibits the nuclear factor-k $B$ transcriptional activity in Rat-1 fibroblasts. Biochem Pharmacol 2003; 66(6): 955963. https://doi.org/10.1016/S0006-2952(03)00465-9

Y, Jeong $Y$, Tyner A, Park JHY, Induction of cell cycle arrest and apoptosis in HT-29 human colon cancer cells by the dietary compound luteolin. Am J Physiol Gastrointest Liver Physiol 2007; 292(1): G66-G75. https://doi.org/10.1152/ajpgi.00248.2006

[13] Lopez-Lazaro M. Distribution and biological activities of the flavonoid luteolin. Mini Rev Med Chem 2009; 9(1): 31-59. https://doi.org/10.2174/138955709787001712

[14] Sakuma S, Nishioka Y, Imanishi R, Nishikawa K, Sakamoto $\mathrm{H}$, Fujisawa $\mathrm{J}$, et al. cis9, trans11-Conjugated linoleic acid differentiates mouse 3T3-L1 preadipocytes into mature small adipocytes through induction of peroxisome proliferatoractivated receptor Y. J Clin Biochem Nutr 2010; 47(2): 167173.

https://doi.org/10.3164/jcbn.10-44

[15] Sakuma S, Fujisawa J, Sumida M, Tanigawa M, Inoda R, Sujihera $\mathrm{T}$, et al. The involvement of mitogen-activated protein kinases in the 1a,25-dihydroxy-cholecalciferolinduced inhibition of adipocyte differentiation in vitro. J Nutr Sci Vitaminol 2012; 58(1): 1-8. https://doi.org/10.3177/jnsv.58.1

[16] Sakuma S, Sumida M, Endoh $Y$, Kurita A, Yamaguchi A Watanabe $\mathrm{T}$, et al. Curcumin inhibits adipogenesis induced by benzyl butyl phthalate in 3T3-L1 cells. Toxicol Appl Pharmacol 2017; 329: 158-164 https://doi.org/10.1016/j.taap.2017.05.036

[17] Sottile V, Seuwen K. Bone morphogenetic protein-2 stimulates adipogenic differentiation of mesenchymal precursor cells in synergy with BRL 49653 (rosiglitazone). FEBS Lett 2000; 475(3): 201-204. https://doi.org/10.1016/S0014-5793(00)01655-0

[18] Schubert $M$, Becher S, Wallert $M$, Mae $\beta$ MB, Abhari $M$, Rennert $\mathrm{K}$, et al. The Peroxisome Proliferator-Activated Receptor (PPAR)-Y Antagonist 2-Chloro-5-Nitro-NPhenylbenzamide (GW9662) Triggers Perilipin 2 Expression via PPARס and Induces Lipogenesis and Triglyceride Accumulation in Human THP-1 Macrophages. Mol Pharmacol 2020; 97(3): 212-225. https://doi.org/10.1124/mol.119.117887

[19] Jia Y, Wu C, Kim J, Kim B, Lee SJ. Astaxanthin reduces hepatic lipid accumulations in high-fat-fed C57BL/6J mice via activation of peroxisome proliferator-activated receptor (PPAR) alpha and inhibition of PPAR gamma and Akt. J Nutr Biochem 2016; 28: 9-18 https://doi.org/10.1016/j.jnutbio.2015.09.015

[20] Shehzad A, Khan S, Lee YS. Curcumin molecular targets in obesity and obesity-related cancers. Future Oncol 2012; 8(2): 179-190.

https://doi.org/10.2217/fon.11.145

[21] Gebhardt R. Inhibition of cholesterol biosynthesis in primary cultured rat hepatocytes by artichoke (Cynara scolymus L.) extract. J Pharmacol Exp Ther 1998; 286(3): 1122-1128. URL: $\quad$ https://jpet.aspetjournals.org/content/jpet/286/3/ 1122.full.pdf 
[22] Baker RG, Hayden MS, Ghosh S. NF-kB, Inflammation, and Metabolic Disease. Cell Metab 2011; 13(1): 11-22. https://doi.org/10.1016/j.cmet.2010.12.008

[23] Liu Y, Fu X, Lan N, Li S, Zhang J, Wang S, et al. Luteolin protects against high fat diet-induced cognitive deficits in obesity mice. Behav Brain Res 2014; 267: 178-88. https://doi.org/10.1016/j.bbr.2014.02.040

[24] Xu N, Zhang L, Zhang X, Chen YG, Bao B, Liu J. Low-dose diet supplement of a natural flavonoid, luteolin, ameliorates diet-induced obesity and insulin resistance in mice. Mol Nutr Food. Res 2014; 58(6): 1258-1268. https://doi.org/10.1002/mnfr.201300830

[25] Kwon EY, Jung UJ, Park T, Yun JW, Choi MS. Luteolin attenuates hepatic steatosis and insulin resistance through the interplay between the liver and adipose tissue in mice with diet-induced obesity. Diabetes 2015; 64(5): 1658-1669. https://doi.org/10.2337/db14-0631

[26] Abu Bakar FI, Abu Bakar MF, Rahmat A, Abdullah N, Sabran SF, Endrini S. Anti-gout potential of Malaysian medicinal plants. Front Pharmacol 2018; 23(9): 261. https://doi.org/10.3389/fphar.2018.00261

[27] Liu P, Xu H, Shi Y, Deng L, Chen X. Potential molecular mechanisms of plantain in the treatment of gout and hyperuricemia based on Network Pharmacology. Evid Based Complement Alternat Med 2020; 2020: 3023127. https://doi.org/10.1155/2020/3023127 